\title{
A study on effects of leadership style on innovation: A case study from automaker industry
}

\author{
Jamal Abdolmaleki $^{a^{*}}$, Morteza Amani Ashloublagh ${ }^{b}$, Mohsen Ameri Shahrabi $^{c}$, Alieh Kazemi Ashlaghi \\ and Saeid Safdari ${ }^{\mathrm{d}}$
}

${ }^{a}$ PhD Student in Educational Planning, Shahid Beheshti University, Tehran, Iran

${ }^{b} \mathrm{PhD}$ Candidate in Education Management, Kharazmi University, Tehran, Iran

${ }^{c}$ Department of English and Management, Naragh Branch, Islamic Azad University, Naragh, Iran

${ }^{d}$ Department of Management, Naragh Branch, Islamic Azad University, Naragh, Iran

\section{A R T I C L E I N F O \\ A B S T R A C T}

Article history:

Received January 10, 2013

Received in Revised form

March, 26, 2013

Accepted 17 June 2013

Available online

18 June 2013

Keywords:

Leadership style

Innovation

Iran Khodro

\begin{abstract}
Leadership is one of the most important components of management in any business unit. An organization with good leadership tends to have a better chance to survive in todays' competitive environment. This paper considers the effects of leadership style on innovation in one of the biggest automakers in Iran named Iran Khodro. The proposed study of this paper designs a questionnaire and distributes it among a sample of 278 regular employees and 61 middle level managers of this firm. The results of the survey indicate that there is a meaningful difference between leadership style and standard leadership style among middle level managers when the level of significance is five percent. In addition, there is a meaningful difference between innovation and its components with standards among regular employees. Finally, leadership has positive and meaningful impact on employees' innovation.
\end{abstract}

2012 Growing Science Ltd. All rights reserved.

\section{Introduction}

During the past few years, there have been tremendous efforts on measuring the effects of leadership on performance of organizations. There is no doubt that different leadership styles have various impacts on firms' components such as innovation, organizational change, etc. (Ehigie \& Akpan, 2004) Iravani et al. (2012) studied the relationship between leadership style among teachers who worked in high schools and their orientation on organizational change. The reported that there was no meaningful relationship between leadership style and gender, leadership style and job experience, organizational change and gender, management change and gender. Sehhat et al. (2012) investigated the relationship between informal communications with leadership style in some of governmental organizations located in free islands of Chabahar, in south east part of Iran. They reported that there was a positive and meaningful relationship between leadership style and informal relationships.

* Corresponding author

E-mail addresses: j_abdolmaleki@sbu.ac.ir (J Abdolmaleki) 
Moghaddas Pour et al. (2012) performed an investigation on relationship between relationshiporiented leadership style and solution-oriented strategy as well as between leadership style and conflict management. The proposed study distributed a questionnaire among 43 managers who were in different industries in west part of Iran. They considered relationship between leadership style and conflict management, which includes the relationship between relationship-oriented and task-oriented leaderships with avoiding conflict management strategy, solution and control based conflict managements. The results confirmed that there was only a meaningful relationship between relationship-oriented leadership with solution-based conflict management. In other words, their survey confirmed that when there was a conflict, management could handle the problem using his/her relationship and find appropriate solution to resolve any possible conflict.

Morshedian Rafiee and Mohammadi (2012) investigated the relationship between leadership style and self-esteem. The survey considered four groups of leadership style including autocratic-charity, autocratic-exploitation, management consulting and participative and their effects on self-esteem. The results of the survey indicate that there was a positive and strong relationship between participative leadership management style and self-esteem. The results also indicated that there was a strong relationship between educational background and self-esteem.

Derakhshandeh and Gholami (2012) studied the relationship between leadership style and perceived organizational effectiveness by directors and managers in organizations. The proposed study distributed a questionnaire consists of 37 questions among some management team of Agricultural ministry in one of the provinces of Iran. They examined the positive relationship between leadership style and perceived organizational effectiveness. The results of Spearman-Pearson test confirmed that there was a meaningful and positive relationship between leadership style and perceived organizational effectiveness. Malmir et al. (2013) reviewed recent advances on leadership style and various perspectives of organizational cultures completed during the past few years.

Shalley and Gilson (2004) presented a comprehensive review of research examining contextual factors that can either foster or hinder employee creativity at the individual, job, group, and organizational level. They investigated the role of leadership and the use of various human resource practices for developing a work context that is supportive of creativity. They discussed practical implications for managers, proposed areas that needed further research attention, and highlight possible new directions for future research.

Oldham and Cummings (1996) examined the independent and contributions of employees' creativityrelevant personal characteristics and three specifications of the organizational context-job complexity, supportive supervision, and controlling supervision - to three indicators of employees' creative performance; patent disclosures written, contributions to a firm suggestion program, and supervisory ratings of creativity. According to Mumford (2003) and Mumford and Licuanan (2004), the need for innovation in organizations has resulted in a new concentration on the role of leaders in shaping the nature and success of creative efforts. De Jong and Den Hartog (2007) provided an inventory of leader behaviors likely to enhance employees' innovative behavior, including idea generation and application behavior. According to Anderson et al. (2004) facilitators of innovation at the individual, group, and organizational levels were not well identified and suggested more discussion on this issue.

\section{The proposed study}

The proposed study of this paper tries to find the present conditions of leadership style among middle levels managers who work for one of the biggest automakers in Middle East called Iran Khodro. The survey also tries to rank different leadership styles among middle levels managers. We plan to find out the present circumstances of innovation in this business unit and using some statistical techniques, 
we rank them, accordingly. Finally, we try to find our whether innovation has any impact leadership style. The proposed study of this paper designs a questionnaire and distributes it among a sample of 278 regular employee and 61 middle level managers of this firm. The study uses Cronbach alpha to verify the questions of the survey and this figure was calculated for 20 questions of leadership style as 0.89. In addition, Cronbach alpha has been calculated for 22 questions of innovation as 0.92 . These numbers are well above the minimum acceptable level of 0.7 and they validate the overall questionnaire of this survey. The proposed study of this paper uses structural equation modeling to investigate the information. Table 1 summarizes the results of some basic statistics.

\section{Table 1}

The summary of some basic statistics on macro scale

\begin{tabular}{lllll}
\hline Row & Scale & Frequency & Mean & Standard deviation \\
\hline 1 & Leadership style & 61 & 2.92 & 0.287 \\
2 & Innovation & 278 & 2.16 & 0.201 \\
\hline
\end{tabular}

In addition, Table 2 demonstrates mean and standard deviation for four different leadership styles including autocratic-charity, autocratic-exploitation, management consulting and participative.

\section{Table 2}

The summary of some basic statistics on leadership components

\begin{tabular}{lllll}
\hline Row & Component & Frequency & Mean & Standard deviation \\
\hline 1 & Transformational Style / Convertible & 61 & 2.79 & 0.253 \\
2 & Light situational / contingency & 61 & 2.66 & 0.219 \\
3 & Style democratic / participative & 61 & 2.32 & 0.238 \\
4 & Light servant & 61 & 2.44 & 0.245 \\
\hline
\end{tabular}

Finally, Table 3 demonstrates the results of basic statistics associated with innovation components.

\section{Table 3}

The summary of some basic statistics on innovation components

\begin{tabular}{llccc}
\hline Row & Component & Frequency & Mean & Standard deviation \\
\hline 1 & Environmental innovation & 278 & 2.31 & 0.319 \\
2 & Leadership innovation & 278 & 2.44 & 0.308 \\
3 & Individual innovation & 278 & 2.51 & 0.218 \\
4 & Environment - Feedback & 278 & 2.39 & 0.318 \\
5 & Individual-Feedback & 278 & 2.52 & 0.214 \\
\hline
\end{tabular}

\section{The results}

In this section, we present details of our findings on testing various hypotheses.

\subsection{The first hypothesis: Leadership condition}

The first question of the survey investigates leadership circumstances in this organization. Table 4 demonstrates the results of t-student on each leadership component.

\section{Table 4}

The summary of some t-student test on leadership components

\begin{tabular}{llllll}
\hline Row & Component & Mean & Standard deviation & t-value & Sig. \\
\hline 1 & Transformational Style / Convertible & 2.79 & 0.253 & 4.56 & 0.01 \\
2 & Light situational / contingency & 2.66 & 0.219 & 3.81 & 0.01 \\
3 & Style democratic / participative & 2.32 & 0.238 & 2.54 & 0.01 \\
4 & Light servant & 2.44 & 0.245 & 3.78 & 0.01 \\
\hline
\end{tabular}


As we can observe from the result of Table 4, all t-student are statistically significance with $\alpha=0.05$. Therefore, the first hypothesis of this survey is confirmed and we can conclude that leadership styles are different among middle level of management team in this business unit.

\subsection{Ranking leadership styles: Freedman test}

The second question of this survey is associated with ranking different components of leadership style using Freedman test. Table 5 demonstrates the results of the test.

\section{Table 5}

The summary of some Freedman statistics on leadership components

\begin{tabular}{llcc}
\hline Row & Component & Mean & Ranks \\
\hline 1 & Transformational Style / Convertible & 3.72 & 1 \\
2 & Light situational / contingency & 3.28 & 3 \\
3 & Style democratic / participative & 3.46 & 2 \\
4 & Light servant & 2.80 & 4 \\
\hline Chi-Square $=$ & 1857.21 df $=1$ Sig. $=0.01$ & &
\end{tabular}

According to the results of Table 5, Transformational Style / Convertible is number one priority followed by Style democratic / participative, Light situational / contingency and Light servant.

\subsection{Innovation circumstances}

The third question of the survey investigates innovation circumstances within organization and we use t-student test to verify the components, which are given in Table 6 as follows,

\section{Table 6}

The summary of some basic statistics on innovation components

\begin{tabular}{llcccc}
\hline Row & Component & Mean & Standard deviation & t-value & Sig. \\
\hline 1 & Environmental innovation & 2.31 & 0.319 & 5.36 & 0.01 \\
2 & Leadership innovation & 2.44 & 0.308 & 3.45 & 0.01 \\
3 & Individual innovation & 2.51 & 0.218 & 4.17 & 0.01 \\
4 & Environment - Feedback & 2.39 & 0.318 & 4.89 & 0.01 \\
5 & Individual-Feedback & 2.52 & 0.214 & 3.69 & 0.01 \\
6 & Innovation & 2.31 & 0.319 & 2.98 & 0.01 \\
\hline
\end{tabular}

The results of Table 6 clearly show that all components on innovations are statistically significant and we can confirm that the levels of innovation components are different from standard levels.

\subsection{Ranking innovation components}

The fourth question of the survey is to find the relative importance of each component of the innovation. Table 7 demonstrates the summary of our survey based on Freedman test.

\section{Table 7}

The summary of Freedman test on innovation components

\begin{tabular}{llcc}
\hline Row & Component & Mean & Rank \\
\hline 1 & Environmental innovation & 3.01 & 4 \\
2 & Leadership innovation & 4.06 & 1 \\
3 & Individual innovation & 3.58 & 2 \\
4 & Environment - Feedback & 3.10 & 3 \\
5 & Individual-Feedback & 2.01 & 5 \\
\hline Chi-Square $=$ & 1657.42 df = 1 Sig. $=0.01$ & &
\end{tabular}


Based on the results of Table 7, Leadership innovation plays the most important item followed by individual innovation, environment-feedback, environmental innovation and individual-feedback comes the last in terms of priority.

\subsection{Relationship between innovation and leadership style}

The last question of this survey is associated with the relationship between innovation and leadership style and in order to study the relationship between these two components we need to perform Pearson correlation test, which yields 0.254 with $\mathrm{P}$-value $=0.001$. This means there is a positive and meaningful relationship between these two components. Next, we perform ANOVA test before implementing linear regression model. Table 8 demonstrates the results of our survey.

Table 8

The summary of ANOVA test

\begin{tabular}{cccccc}
\hline Source of change & Sum of Squares & df & Mean squares & F & Sig. \\
\hline Regression & 13.458 & 3 & 12.89 & 16.45 & 0.01 \\
Error & 11.5 & 274 & 89.1 & & \\
Total & 24.958 & 277 & & & \\
\hline
\end{tabular}

The results of Table 8 clearly show that F-value is statistically meaningful when the level of significance is one percent. Therefore, we can use proceed linear regression analysis and the results are presented in Table 9 as follows,

\section{Table 9}

The summary of regression analysis

\begin{tabular}{|c|c|c|c|c|c|}
\hline Independent variable & $\begin{array}{l}\text { No-standard } \\
\text { coefficients }\end{array}$ & Standard value & $\begin{array}{c}\text { standard } \\
\text { coefficients }\end{array}$ & $\mathrm{T}$ & Sig \\
\hline Intercept & 13.14 & 569 & 245 & 12.15 & 5 \\
\hline Transformational Style / Convertible & 36.8 & 468 & 415 & 2.12 & 5 \\
\hline Light situational / contingency & 19.7 & 311 & 214 & 98.1 & 5 \\
\hline Style democratic / participative & 89.3 & 114 & 116 & 56.8 & 5 \\
\hline Light servant & 2.3 & 215 & 105 & 2.8 & 5 \\
\hline
\end{tabular}

The results of regression between innovation, as dependent variable, and leadership styles as independent variables indicate that all four components statistically maintain significant impact on dependent variable, innovation, and we can confirm the positive relationship between two items.

\section{Conclusion}

In this paper, we have presented an empirical investigation to study the relationship between innovation and leadership style in one of the biggest Iranian automakers. The study has determined that presently this automaker is well away from standards in terms of both leadership style and innovation. In addition, the survey has concluded that innovation is a function of leadership components.

\section{References}

Anderson, N., De Dreu, C. K., \& Nijstad, B. A. (2004). The routinization of innovation research: A constructively critical review of the state-of-the-science. Journal of organizational Behavior, 25(2), 147-173.

De Jong, J. P., \& Den Hartog, D. N. (2007). How leaders influence employees' innovative behaviour. European Journal of Innovation Management, 10(1), 41-64. 
Derakhshandeh, A \& Gholami, R. (2012). A relationship between leadership style and perceived organizational effectiveness by directors and managers in organizations. Management Science Letters, 2(3), 845-850.

Ehigie, B. O., \& Akpan, R. C. (2004). Roles of perceived leadership styles and rewards in the practice of total quality management. Leadership \& Organization Development Journal, 25(1), 24-40.

Iravani, M., Mosavi, S., Movahedi, A., Iravani, G \& Iravani, A. (2012). A social work study on relationship between leadership style and organization change: A case study of Semnan high schools' teachers. Management Science Letters, 2(7), 2377-2382.

Malmir, M., Esfahani, M \& Emami, M. (2013). An investigation on leadership styles in different cultures. Management Science Letters, 3(5), 1491-1496.

Moghaddas Pour, S., Bakhshizadeh, A \& Barati, E. (2012). An empirical study to measure the relationship between management style and conflict management. Management Science Letters, 2(6), 2249-2254.

Morshedian Rafiee, S., \& Mohammadi, M. (2012). Leadership styles and its relationship with subordinates \& quot; self-esteem. Management Science Letters, 2(7), 2457-2462.

Mumford, M. D. (2003). Where have we been, where are we going? Taking stock in creativity research. Creativity Research Journal, 15(2-3), 107-120.

Mumford, M. D., \& Licuanan, B. (2004). Leading for innovation: Conclusions, issues, and directions. The leadership quarterly, 15(1), 163-171.

Oldham, G. R., \& Cummings, A. (1996). Employee creativity: Personal and contextual factors at work. Academy of management journal, 39(3), 607-634.

Sehhat, S., Kenari, M \& Alipour, M. (2012). The effect of informal communication on the leadership styles in governmental organizations. Management Science Letters, 2(7), 2637-2642.

Shalley, C. E., \& Gilson, L. L. (2004). What leaders need to know: A review of social and contextual factors that can foster or hinder creativity. The Leadership Quarterly, 15(1), 33-53. 